\title{
Evaluation of reversal and transposition generational damages caused by manganese (II) in zebrafish
}

Gabriela Zimmermann Prado Rodrigues ( $\square$ gabizpr@gmail.com )

Universidade FEEVALE https://orcid.org/0000-0002-8580-6243

Thainá Garbino dos Santos

Universidade Federal do Rio Grande do Sul

Mariana Finkler

FEEVALE University: Universidade FEEVALE

Jorge Henrique Burghausen

FEEVALE University: Universidade FEEVALE

Diulliane de Jesus Borba

Universidade FEEVALE

Juliana Machado Kayser

Universidade FEEVALE

Bruna Bueno Milanesi

PUCRS: Pontificia Universidade Catolica do Rio Grande do Sul

Anelise Schneider

FEEVALE University: Universidade FEEVALE

Rafael Linden

FEEVALE University: Universidade FEEVALE

Léder Leal Xavier

PUCRS: Pontificia Universidade Catolica do Rio Grande do Sul

Ana Luiza Ziulkoski

FEEVALE University: Universidade FEEVALE

Diogo Losch de Oliveira

UFRGS: Universidade Federal do Rio Grande do Sul

Günther Gehlen

FEEVALE University: Universidade FEEVALE

\section{Research Article}

Keywords: histopathological, locomotor behavior, TUNEL staining 
Posted Date: October 11th, 2021

DOI: https://doi.org/10.21203/rs.3.rs-855463/v2

License: (c) (i) This work is licensed under a Creative Commons Attribution 4.0 International License. Read Full License 


\section{Abstract}

Although manganese $(\mathrm{Mn})$ is a common water pollutant, little is known about the potential for the transgenerational transfer of biological effects in fish exposed to low concentrations in aquatic organisms, or the persistence of these effects. The aim was to identify when biological effects were firstly observed in the brain, liver and intestinal tissues of zebrafish exposed to environmentally relevant concentrations of $\mathrm{Mn}$ and whether these effects were subject to reversal when exposures ceased. We also aimed to assess whether biological effects observed in zebrafish exposed to $\mathrm{Mn}$ for 21-days were also observed in the early life stages of the F1 generation. Behavioral changes were observed in the animals exposed for 14 days to $\mathrm{MnCl}_{2}\left(4.0 \mathrm{mg} \mathrm{L}^{-1}\right)$. There was also an oscillation in the mitochondrial activity and TUNEL positive cells in the telencephalon of exposed fish from all treatments. These results indicated that brain neurogenesis in zebrafish occurred with greater magnitude and speed than the neuronal $\mathrm{Mn}$ damage. Histopathological changes were observed in the intestine and liver of zebrafish exposed to $\mathrm{Mn}$ for $72 \mathrm{~h}$ and 21 days. Behavioral alterations and intestinal histopathological alterations were reversed after the recovery period, although hepatocyte vacuolization persisted. Behavioral alterations were also observed in the early developmental stages of F1 generation larvae of zebrafish parents exposed to Mn, but this profile was normalized throughout the development. In addition to the direct toxic effects of low concentrations of $\mathrm{Mn}$, some changes, such as hepatocyte vacuolization persisted in zebrafish even after the toxicant removal.

\section{Introduction}

Manganese is an essential trace metal for numerous physiological functions in humans and animals and can be found in a wide variety of foods and in some types of grains and seafood (Miah et al. 2020; Peres et al. 2016). It also acts as an activator and cofactor for a variety of metalloenzymes that play a fundamental role in biological functions, such as gluconeogenesis, suppression of oxidative stress, and conversion of glutamate to glutamine (Aschner and Gannon 1994; Getachew et al. 2019). Its deficiency can result in a series of reproductive, growth, and even neurological effects (Roth and Garrick 2003).

Being one of the main metals polluting the water, manganese occurs naturally in igneous, sedimentary, and metamorphic rocks, although it is also used in the manufacture of iron/steel alloys, batteries, glass, fireworks, fertilizers, fungicides, varnishes, and animal supplementation (HSDB 2001; Mena 1980, Patil et al. 2016). Due to its widespread use in the industry sector, manganese has been reported in the most varied water resources in Brazil and other countries in the range of $\mathrm{mg} \mathrm{L}^{-1}$ (Bacquart et al. 2015; Rietzler et al. 2001; Kakkoi et al. 2016; Krützmann et al. 2020; Oliveira and Galvão 2019), mostly occurring in combination with carbonates, sulfates, chlorides, and phosphates, turning its detection difficult (Marsidi et al. 2018).

Sporadically, manganese is also found in drinking water (Alvarez-Bastida et al. 2018; Frisbie et al. 2012; Krützmann et al. 2020) because of the partial removal of this metal during conventional water treatment processes, causing manganese deposition in drinking water distribution systems (Zhou et al. 2020). This 
deposition derives from the manganese concentration in the water source and subsequent transformations that occur in pipes and end up modifying the water color that consumers receive (Li et al. 2019).

Faced with this problem, numerous authors have been studying over the years the harmful effects that high concentrations or prolonged exposures to this metallic pollutant can cause to the whole ecosystem involved, including the health of human beings (Altenhofen et al. 2017; Bjørklund et al. 2017; Bouchard et al. 2018; lyare et al. 2019; Kawamura et al. 1941; Rodrigues et al. 2018; Sarkar et al. 2018). Some findings indicate liver and brain toxicity, including mitochondrial alterations (Liu et al. 2021) and the ability to cross the blood-brain barrier in the developing fetus, newborns, and adults (Bjørklund et al. 2017), causing (in humans) a disease called manganism, which is phenotypically equivalent to Parkinson's disease (Kwakye et al. 2015). Regarding to behavioral alterations, studies indicate the reduction of exploratory behavior in adult and larvae zebrafish (Altenhofen et al. 2017).

Considering that manganese is a worldwide environmental health problem, understanding the mechanisms of action responsible for toxicity, recovery capacity, or reduction of phenotypes resulting from the exposure and generational transposition of those changes is relevant to provide the real longterm severity of the problem. Frequently, several studies evaluated relatively high concentrations that does not reflect the environmental conditions (Altenhofen et al. 2017; Arndt et al. 2014; Wu et al. 2020). In contrast, a manuscript that we recently published (Rodrigues et al. 2020), we demonstrated the effects caused by acute 96 -hour and chronic 30-day exposure to low concentrations of manganese by Danio rerio. From these findings, we decided to refine the toxicity of this pollutant using different exposure periods.

Therefore, in the present study, we aimed to define when the damage began to be observed in the main metabolic organs of zebrafish after different periods of exposure ( 72 hours, 7,14 , and 21 days) to environmentally relevant concentrations of manganese. We also aimed to evaluate whether the damage caused by the 21-day exposure to the contaminant could be transferred to the next generations of animals or subjected to reversion, in the face of hypothetical decontamination of the environment.

\section{Material And Methods}

\section{Experimental procedure - adult fish}

All procedures carried out in this study were previously submitted and approved by the ethics committee on the use of animals at Feevale University (02.18.066). Fishes of the species Danio rerio (wild-type, 6-7 months old, male and female) were obtained from a local standard supplier and acclimatized in the laboratory for 2 months before using them for the experiments in order to exclude any previous stress. The water for the maintenance and experimentation of the animals was reconstituted (ISO, 1996), and the parameters were maintained according to the recommended by the Brazilian Norm NBR 15088. 
In short, the temperature was continually maintained around $26 \pm 2^{\circ} \mathrm{C}, \mathrm{pH}$ between 7 and 8 , the conductivity of $160 \mu \mathrm{S} / \mathrm{cm}$, and hardness between 75-100. The density of animals per aquarium was a maximum of 2 animals per liter of water. The light cycle was 14:10 h light/dark (the lights came on at 7 am), the aquariums were constantly aerated, and the feeding occurred at 8 am and $1 \mathrm{pm}$ with commercial feed (Tetramin $\left.{ }^{\circledR}\right)$, and at $5 \mathrm{pm}$ with Artemia Salina. Such parameters were persistent in both acclimatization and exposure.

The manganese chloride reagent $\left(\mathrm{MnCl}_{2} 4 \mathrm{H}_{2} \mathrm{O}\right.$, LabSynth ${ }^{\circledR}, 98 \%$ purity) was used to prepare a stock solution, which was subsequently diluted in the aquariums to reach concentrations of 0.5 and $4.0 \mathrm{mg} \mathrm{L}^{-1}$ of $\mathrm{MnCl}_{2}$ (in which each $1 \mathrm{mg} \mathrm{L}^{-1}$ of $\mathrm{MnCl}_{2}$ corresponds to $0.28 \mathrm{mg} \mathrm{L}^{-1}$ of manganese since manganese represents $27.8 \%$ of the mass of $\mathrm{MnCl}_{2} 4 \mathrm{H}_{2} 0$ ), according to a study previously published (Rodrigues et al. 2020). Water changes, both in the acclimatization and exposure and recovery periods, occurred every 48 hours.

The study consisted of three stages: (1) chronic exposure to $\mathrm{MnCl}_{2}$ for 21 days, (2) reproduction at the end of these 21 days, and (3) the cultivation of fry to visualize possible changes in the offspring, and the transferring of some animals at the end of 21 days for decontaminated water, called as the recovery period. In all sampling periods (experimental), the animals were divided into three groups: Control group, $\mathrm{MnCl}_{2} 0.5 \mathrm{mg} \mathrm{L}^{-1}$, and $\mathrm{MnCl}_{2} 4.0 \mathrm{mg} \mathrm{L}^{-1}$.

For chronic exposure, 72 animals were used and, over the 21 days, part of the animals was sacrificed at different times ( 72 hours, 7,14 , and 21 days) (12 animals for each period of sampling / per group), aiming to identify from how long exposure would be possible to observe changes caused by $\mathrm{MnCl}_{2}$.

At the end of the 21 days of exposure, each group was submitted to the reproduction protocol in aquariums without the addition of $\mathrm{MnCl}_{2}$, to ensure that the embryos collected never had contact with the metal.

In the period called recovery, part of the animals (24 per group) was transferred to aquariums containing only the reconstituted water (without the addition of $\mathrm{MnCl}_{2}$ ) and kept for 30 days to identify whether the possible damage found would be susceptible to reversion in the face of a decontaminated environment.

All adult animals, either at the end of the exhibitions or the recovery period, underwent analysis as described below.

\section{Behavioral analysis}

At the end of each exposure (72 hours, 7, 14, and 21 days) and the recovery period, the animals were submitted to the open tank test (Rodrigues et al. 2020) ( $n=12$ per group, except in the recovery period when $n=24$ ). Briefly, the apparatus consisted of a $20 \times 20 \times 10 \mathrm{~cm}$ aquarium (height $x$ length $\times$ width), and the animals were filmed for 6 minutes and then evaluated using the ANY-maze software, which 
evaluated the following parameters: average speed, moving time, distance traveled, number of entries in the top, middle, and bottom zones of the tank, as well as the distance traveled, and the time spent in each zone. At the end of the behavioral experiment, the animals were anesthetized and sacrificed with tricaine $\left(160 \mu \mathrm{gL}^{-1}\right)$ to continue the other assays.

\section{MTT assay}

In order to identify possible mitochondrial changes, the mitochondrial viability assay was carried out with MTT (3- (4,5-dimethylthiazole - 2-yl bromide) -2,5-diphenyltetrazolium) in the animals' telencephalons. The set of samples for processing consisted of the homogenized telencephalons (that is, 2 animals represent 1 pool), totaling 3 pools per group, and a total $n$ of 6 animals used for this assay. Half of the sample volume was directed to the protein dosage (Lowry method), and the other half was addressed to the quantification of MTT, which occurred according to the described by Rodrigues et al. (2020). The data were normalized and expressed in the absorbance obtained by reading the MTT in $50 \mu \mathrm{g}$ of protein (average protein concentration per sample).

\section{Histopathological analyses}

For each day of sampling, tissues from the liver $(n=3)$, brain $(n=3)$, and intestines $(n=5)$ were removed for microscopic analysis. The samples were fixed in $4 \%$ formaldehyde, embedded in paraffin, and sectioned in a $5 \mu \mathrm{m}$ thick rotating microtome (Dalzochio et al. 2018; Rodrigues et al. 2020).

The liver slides were stained with hematoxylin and eosin. Three images of each animal were captured with a camera attached to the optical microscope (Nikon Eclipse E200-400x of magnification). In each image, the total number of hepatocytes was recorded, including the number of normal and altered cells (hypertrophy, cell vacuolization, hyperemia, aneurysm, and degeneration) as describe by Bernet et al. (1999).That was differentiated for later calculation of the percentage in relation to the control.

In the liver, in addition to HE morphological analysis, other images were captured with the aid of a camera (AXIOCAM ICM1 model) coupled to a ZEISS microscope (Axio Scope. A1) for better disclosure and contrast of the nuclei in the hepatocytes. Approximately 500 nuclei were evaluated per group in each sample period. The methodology described by Filippi-Chiela and collaborators (2012) was used for the nuclear morphometric analysis. Briefly, through a plug-in of the Image ProPlus software, 500 cores were evaluated for their morphology and size.

The control group nuclei are used to define the parameters of the normal population and to classify the other nuclei of the experiment in: Normal (N), Irregular (I), Small Regular (SR), Small (S), Small Irregular (SI), Large Regulars (LR), and Large Irregulars (I). Measures recorded by the software itself (aspect, area, radius ratio, and rounding) are combined and determine the Nuclear Irregularity Index (NII) as made available and described by the authors of the methodology. The nuclear area and NII data are used to plot the graphs, and the Nuclear Irregularity Index is calculated for each nucleus through the following mathematical formula: $\mathrm{NII}=0.9 \times$ Aspect $-0.87 \times$ Area/Box $+0.96 \times$ RadiusRatio $+0.92 \times$ Roundness (Filippi-Chiela et al. 2012). 
The intestine slides were stained with alcian blue and hematoxylin (Rodrigues et al. 2018) to show the goblet cells. Subsequently, images of the sections were captured with the aid of a camera attached to the optical microscope (Nikon Eclipse E200-400x magnification), and, in general, 50 villi per group (five images containing 2 villi per image per animal) were analyzed to find the presence or absence of infiltration of blood cells, such as leukocytes, and fusion of villi. The percentage of these changes was calculated for each animal and group. The number of goblet cells was also recorded in the 50 villi of each group.

To identify possible cells in apoptosis in the telencephalic region, we guided ourselves through the zebrafish neuroanatomy atlas (Wullimann, Rupp and Reichert 1996) and a previous publication performed by the group (Rodrigues et al. 2020). The sections of the ventral region of the telencephalon, specifically the periventricular area in the dorsal nucleus $(\mathrm{Vd})$, were located and selected from 03 animals per group in each exposure period ( $72 h, 7,14,21$ days and recovery). The slides were stained with TUNEL, according to the manufacturer's specifications (In Situ Cell Death Detection Kit, Fluorescein; SigmaAldrich. Cat. No. 11684795 910), with the addition of a dilution factor (1:20) in the kit, due to better marking.

Briefly, the slides were deparaffinized, hydrated, washed with a PBS-Triton $\mathrm{x} \%$ tissue pretreatment solution for 08 minutes, and incubated in the TUNEL mixing solution for 01 hour $\left(37^{\circ} \mathrm{C}\right)$ in the total absence of light. Subsequently, the sections were washed (3x) with PBS buffer and mounted with Fluoroshield with DAPI (Sigma). The negative control consisted of a mixture without enzyme solution. The slides were visualized under a fluorescence microscope (Zeiss Axio Scope.A1), through the green filter for cells stained with TUNEL (excitation range $450-500 \mathrm{~nm}$ and detection range 515-565 nm) and filter for DAPI (excitation: 365 and issue 445/50). Images were captured with the aid of a CMOS camera (model AXIOCAM ICM1) coupled to a microcomputer containing the ZEN2 software. The analysis consisted of observing 05 areas of interest in the size of $2 \mu \mathrm{m} \times 2 \mu \mathrm{m}$ (using the Image-pro Plus software), located in the ventral region of the telencephalon, mentioned above, where it was possible to determine the percentage of nuclei stained with the TUNEL.

\section{Experimental procedure - embryos and larvae}

After exposing (21 days) the parents to $\mathrm{MnCl}_{2}$ and their respective reproductions, the embryos were collected and kept in BOD incubators at $28^{\circ} \mathrm{C}$ with the daily renewal of the reconstituted water (same parameters specified above) and fed with Paramecium sp. infusoria ad libitum, as described by Baggio et al. (2020).

Morphological analysis

During the development, embryos ( $n=20$ per group) were photographed at $5,10,24,48$, and $72 \mathrm{hpf}$ to identify possible morphological changes, and the respective larvae were also photographed 96 hours after fertilization (hpf), 5, 7, and 10 days after fertilization (dpf) to obtain body measurement and ocular distance. 
The microscope used for this analysis was an inverted Olympus IX73 type (4x of magnification) attached to a camera. The software used for the analysis of body measurement and ocular distance was ImageJ.

\section{Behavioral analysis}

At 5,7 , and $10 \mathrm{dpf}$, the larvae were also evaluated for locomotor behavior ( $\mathrm{n}=20$ per group). The larvae were transferred to 24-well plates and filmed for 5 minutes. The analysis was performed using the ANYmaze software, and the following parameters were evaluated: distance covered, moving time, rotations, and absolute angle of rotation.

\section{Determination of apoptosis}

On the last day of maintenance of the larvae (10 dpf), some ( $n=07$ per group) were randomly selected and stained with Acridine Orange (AO) to identify apoptotic cells, according to manuscripts published by numerous authors ( $\mathrm{Li}$ et al. 2019; Qian et al., 2018; Wang et al. 2016). Briefly, the larvae were stained in a solution of $2.5 \mu \mathrm{g} / \mathrm{mL}$ of LA for 30 minutes; then, they were washed $3 x$ in PBS and anesthetized in tricaine $\left(160 \mathrm{mg} \mathrm{mL}^{-1}\right)$. The larvae were photographed under a $4 \mathrm{x}$ inverted fluorescence microscope (Olympus IX73). An analysis was performed through the quantification of the fluorescence intensity in the telencephalic region of each larva. For this, an area of interest (AOI) was inserted into the telencephalic region, and the intensity of the green channel was measured using the ImageJ software.

\section{Statistical Analysis}

The sample size is in agreement with previously published studies using zebrafish as an animal model with similar objectives to ours (Jia et al. 2019; Kawan et al. 2019; Li et al. 2019; Wang et al. 2019). All data were submitted to the two-way ANOVA test, aiming to find differences between the different groups (control, 0.5 , and $4.0 \mathrm{mg} \mathrm{L}^{-1}$ ) within each sample period ( $72 \mathrm{~h}, 7,14,21$ days and recovery) and between the sampling periods, aiming to identify mainly if the recovery would bring any positive effect to the animals. Except for the results obtained in the acridine orange staining in the larvae, in which the data were submitted to the one-way ANOVA test. For all data, the chosen post-hoc was the Tukey test. The statistical software used to conduct the analyzes was GraphPad Prism.

\section{Results}

\section{Experimentation parameters in aquariums}

Water aliquots used for the sample representation of each aquarium were collected for manganese quantification (performed by Graphite Furnace Atomic Absorption Spectrometry (GFAAS PinAacle 900Z) with Zeeman background correction) on the first and on the last day of the experiment. On the first day, the quantified concentrations of manganese in the water aquariums from the control group, $\mathrm{MnCl}_{2} 0.5$ $\mathrm{mg} \mathrm{L}^{-1}$, and $\mathrm{MnCl}_{2} 4.0 \mathrm{mg} \mathrm{L}^{-1}$ were $0.003,0.148$ and $1.13 \mathrm{mg} \mathrm{L}^{-1}$, respectively. On the last day of the experiment, the same order of the aquariums was followed, and the concentrations were $0.001,0.150$ and 
$1.10 \mathrm{mg} \mathrm{L}^{-1}$. Within the recovery period, concentrations were also measured on the first day $(0.003,0.002$ and $\left.0.003 \mathrm{mg} \mathrm{L}^{-1}\right)$ and on the last day of the experiment $\left(0.002,0.002\right.$ and $\left.0.003 \mathrm{mg} \mathrm{L}^{-1}\right)$. All values corroborate with the expected data for each concentration. Equipment conditions were according Manfro et al. (2020), as the method detection limit was $0.1 \mu \mathrm{g} \mathrm{L}^{-1}$ and the method quantification limit was $0.3 \mu \mathrm{g}$ $\mathrm{L}^{-1}$.

\section{Adult fish}

\section{Behavioral analysis}

Animals chronically exposed to $\mathrm{MnCl}_{2}$ over 21 days did not show significant behavioral damages. Observing the average swimming speed performed by the fish during the test (Fig. 1A), there was no significant difference comparing the groups within the same experimental period $(p=0.55)$, as in the comparison between the same groups from different sample periods $(p=0.79)$. There were also no significant differences in the total distance traveled by the animals, except between the groups $0.5 \mathrm{mg} \mathrm{L}^{-1}$ and $4.0 \mathrm{mg} \mathrm{L}^{-1}$ (Fig. 1B) $(\mathrm{p}=0.016)$, in which the swimming activity of the animals exposed to the highest concentration was reduced compared to animals of the lowest concentration.

After 14 days of the experiment, the animals from the $4.0 \mathrm{mg} \mathrm{L}^{-1}$ group demonstrated an increase in the traveled distance in the top zone of the aquarium compared to the animals of the control group $(p=0.03)$ (Fig. 1D). This profile is maintained in the 21-days specimens' exposure (even if there is no statistical difference). However, after the recovery period, the animals exposed to both concentrations of $\mathrm{MnCl}_{2}$ demonstrated similar general results compared to the control group.

Observing the exploratory activity performed by the animals at the bottom zone of the aquarium (Fig. $1 \mathrm{G}$ and $1 \mathrm{H}$ ), the animals from the $0.5 \mathrm{mg} \mathrm{L}^{-1}$ group traveled a greater distance compared to the animals from the $4.0 \mathrm{mg} \mathrm{L}^{-1}$ group over the 21 days of exposure, with a statistical difference in 72 hours $(p=0.0017)$. However, this behavioral pattern disappears after the animals' recovery period $(p=0.0054)$.

\section{MTT assay and TUNEL staining}

The MTT assay performed on the animals' telencephalon to assess cellular mitochondrial activity did not demonstrate any dose-dependent response pattern (Fig. 2C). There was a greater oscillation in the animals' response in the $4.0 \mathrm{mg} \mathrm{L}^{-1}$ of $\mathrm{MnCl}_{2}$, with a smaller mitochondrial activity of telencephalon cells in 72-hour, 7-day, and 21-day specimens compared to the recovery specimens $(p<0.05)$. It is noteworthy that after 21 days of exposure, a visual trend towards reduction of mitochondrial activity was observed in animals from both concentrations of $\mathrm{MnCl}_{2}$, and this difference was significant in the $4.0 \mathrm{mg} \mathrm{L}^{-1}$ group compared to the animals from the same group in the recovery period $(p=0.0002)$.

Regarding the number of apoptotic cells stained by the TUNEL, we can observe a considerable oscillation in the animals' response exposed to $0.5 \mathrm{mg} \mathrm{L}^{-1}$ of $\mathrm{MnCl}_{2}$. It was observed a lower number of apoptotic 
cells counted in the telencephalon of the animals exposed to $4.0 \mathrm{mg} \mathrm{L}^{-1}$ of $\mathrm{MnCl}_{2}$ in 72 hours $(p=0.005)$, but there was also a tendency (not significant) to increase the percentage of TUNEL positive cells in these animals during the 21 days, even in the recovery period (Fig. 2B and 2D).

\section{Histopathological analysis}

Throughout the intestinal histopathological analysis, animals exposed to both concentrations of $\mathrm{MnCl}_{2}$ demonstrated a tendency to increase the percentage of intestinal changes, as can be seen in Table 1 . Specifically, in the 14th day, animals exposed to $4.0 \mathrm{mg} \mathrm{L}^{-1}$ of $\mathrm{MnCl}_{2}$ showed an increase in the percentage of cellular infiltrate $(\%)$ compared to the control group $(p=0.013)$.

In general, animals exposed to $4.0 \mathrm{mg} \mathrm{L}^{-1}$ of $\mathrm{MnCl}_{2}$ showed a higher percentage of fused villi (Table 1 ). Sporadically, in the 7th day of experimentation, the animals exposed to $0.5 \mathrm{mg} \mathrm{L}^{-1}$ showed a higher fusion rate in their villi, which statistically differed from the control group $(p=0.009)$. However, the same group returned to the profile absence of villus fusions after the recovery period $(p=0.015)$. 
Table 1

Percentage of changes (cell infiltrate and villus fusion) and goblet cells in the 50 villi analyzed per group, expressed as mean \pm standard error. Grey quadrants highlight statistical differences, where uppercase letters differ from lowercase and represent the statistical differences between different groups but within the same sample period. Different letters represent statistical differences within the same group but at distinct sample periods. The lack of letters demonstrates the absence of a statistically significant difference

\begin{tabular}{|c|c|c|c|c|}
\hline & & Cellular infiltrate & Villous fusion & Goblet cells \\
\hline \multirow[t]{5}{*}{ Control group } & 72 hours & $36 \pm 19.31$ & $4 \pm 4$ & $28.08 \pm 3.9$ \\
\hline & 7 days & $35 \pm 9.57$ & $0 \pm 0^{\mathrm{a}}$ & $17.05 \pm 0.55$ \\
\hline & 14 days & $12 \pm 4.89^{a}$ & $0 \pm 0$ & $15.6 \pm 2.39$ \\
\hline & 21 days & $28 \pm 8$ & $0 \pm 0$ & $20.4 \pm 3.06$ \\
\hline & Recovery & $12 \pm 4.89$ & $4 \pm 4$ & $15.6 \pm 4.36$ \\
\hline \multirow[t]{5}{*}{0.5 mg L-1 } & 72 hours & $40 \pm 18.94$ & $0 \pm 0^{b}$ & $22.64 \pm 2.15$ \\
\hline & 7 days & $60 \pm 14.12$ & $16 \pm 7.48^{A}$ & $23.52 \pm 3.02$ \\
\hline & 14 days & $33.33 \pm 13.33$ & $0 \pm 0^{b}$ & $22.93 \pm 2.45$ \\
\hline & 21 days & $45 \pm 9.57$ & $0 \pm 0^{b}$ & $19.4 \pm 2.61$ \\
\hline & Recovery & $40 \pm 10.95$ & $0 \pm 0^{\mathrm{b}}$ & $24.24 \pm 3.36$ \\
\hline \multirow[t]{5}{*}{4.0 mg L-1 } & 72 hours & $44 \pm 7.48$ & $4 \pm 4$ & $28.4 \pm 8.61$ \\
\hline & 7 days & $66.66 \pm 13.33$ & $6.87 \pm 6.87$ & $14.73 \pm 2.08$ \\
\hline & 14 days & $60 \pm 12.64^{A}$ & $4 \pm 4$ & $16.28 \pm 2.15$ \\
\hline & 21 days & $64 \pm 14.69$ & $4 \pm 4$ & $18.6 \pm 3.39$ \\
\hline & Recovery & $39.80 \pm 0.20$ & $4 \pm 4$ & $18.48 \pm 1.76$ \\
\hline
\end{tabular}

Regarding the liver histopathological analysis, the animals exposed to both concentrations of $\mathrm{MnCl}_{2}$ demonstrated a significant reduction in the normal hepatocyte percentage compared to the control group in 72 hours, 7 days, and 21 days of experimentation (Fig. 3A). After the recovery period, the animals exposed to both concentrations had a significant increase in the normal hepatocyte percentage, highlighting the organ's regenerative capacity $(p<0.05)$.

Degeneration and cytoplasmic vacuolization were the most incident alterations in relation to the animals of the control group (Supplementary Table 1) and these conditions were responsible for the reduction of normal hepatocytes in animals exposed to $\mathrm{MnCl}_{2}$. Vacuolization proved to be a persistent change even after the recovery period in decontaminated water, since the animals showed a high rate of this alteration 
over experimentation, especially the specimens of $4.0 \mathrm{mg} \mathrm{L}^{-1}(\mathrm{p}<0.05)$. In contrast, hepatocyte degeneration had its rate reduced in both concentrations after the recovery period $(p<0.05)$.

Regarding the $\mathrm{NII}$, the animals exposed to $4.0 \mathrm{mg} \mathrm{L}^{-1}$ of $\mathrm{MnCl}_{2}$ showed a higher rate of nuclear irregularity in their hepatocytes $(p=0.011)$ after 72 hours, a fact that can be attributed to the presence of some larger nuclei, as can be seen in Figs. 3B-3F. However, this profile is reversed after the recovery period, i.e., the animals' hepatocytes of the $4.0 \mathrm{mg} \mathrm{L}^{-1}$ have a closer nucleus shape to those belonging to the control group $(p<0.0001)$.

\section{Embryos and larvae}

In order to identify the generational transposition of possible alterations caused by $\mathrm{MnCl}_{2}$, some fishes were selected at the end of the 21-day exposure for the reproduction process in decontaminated water. The resulting embryos were collected and cultured until 10 days of life. Throughout the embryonic development, morphological analysis was performed; however, a low frequency of morphological damages was observed without statistical difference among the groups and between the sample periods (as shown in Supplementary Fig. 1). When the individuals reached the larval stage, two parameters started to be registered: body length and ocular distance (Fig. 4B and 4C). We observed an increase in the body length of larvae from parents exposed to $0.5 \mathrm{mg} \mathrm{L}^{-1}$ of $\mathrm{MnCl}_{2}$, especially at 5 and 7 days after fertilization (dpf) $(p<0.01)$. In contrast, 96 hours after fertilization (hpf), these same larvae showed a reduction in ocular distance $(\mathrm{p}<0.0001)$. At $5 \mathrm{dpf}$, larvae from parents exposed to $4.0 \mathrm{mg} \mathrm{L}^{-1}$ of $\mathrm{MnCl}_{2}$ showed an increased ocular distance $(p=0.0001)$.

Throughout the development, the swimming behavior of these larvae was also recorded (Fig. 4D - 4G). In $5 \mathrm{dpf}$, larvae from parents exposed to 0.5 and $4.0 \mathrm{mg} \mathrm{L}^{-1}$ showed an increase in the moving time during the test $(p<0.01)$. On the other days of testing ( 7 and $10 \mathrm{dpf})$, there was a tendency (not significant) to decrease the moving time in the individuals from both groups. Observing the covered distance during the test $(5 \mathrm{dpf})$, the individuals in the $0.5 \mathrm{mg} \mathrm{L}^{-1}$ group showed an increase in the traveled distance in relation to the control $(p=0.49)$. Larvae from parents exposed to $0.5 \mathrm{mg} \mathrm{L}^{-1}$ also had a higher number of rotations throughout the test, especially at $5 \mathrm{dpf}$ and $7 \mathrm{dpf}(\mathrm{p}<0.001)$. The same profile is observed in the absolute angle of rotation of these animals at $5 \mathrm{dpf}(\mathrm{p}<0.0001)$.

Corroborating the absence of behavioral changes at $10 \mathrm{dpf}$, there were also no significant differences in the fluorescence intensity emitted by acridine orange in the telencephalic region of the evaluated larvae $(p=0.218)$, indicating the absence of apoptosis in the studied region (Fig. 5).

\section{Discussion}

Manganese itself preferentially accumulates in the cellular mitochondria (Gunter 2006; Sarkar et al. 2018) through the mitochondrial $\mathrm{Ca} 2+$ uniporter, where it binds to the mitochondrial membrane or matrix proteins (Gavin et al. 1999). Due to this preference, Mn can disrupt mitochondrial function by three main 
mechanisms: inhibiting energy transduction, inducing mutations in the mitochondrial genome, and through the improved generation of free radicals. All forms are interconnected and possibly result in metabolic dysfunction (Brown and Taylor 1999).

Mitochondria is involved in the intrinsic pathway of cell apoptosis (the path by which we believe to justify the findings of our study) due to the activity of releasing cytochrome $c$ from the intermembrane space to initiate the activation of caspases in the cell cytosol (Wang and Youle 2009). In vertebrates, the release of these proteins is a consequence of compromising the integrity of the permeabilization of the outer mitochondrial membrane, which acts controlling the pro-apoptotic members of the Bcl-2 family (Martinou and Youle 2011). The permeabilization of the outer mitochondrial membrane can occur through an increase in the reactive oxygen species (ROS) production in the mitochondria. It contributes to the permeabilization of the inner mitochondrial membrane and triggers a series of factors that will consequently result in the complete loss of the mitochondrial function (Solá et al. 2013).

In the present study, we detected significant differences in the percentage of apoptotic cells stained with TUNEL in the zebrafish telencephalon exposed to $\mathrm{MnCl}_{2}$ (at $4.0 \mathrm{mg} \mathrm{L}^{-1}$ for 72 hours), and the tendency to increase TUNEL positive cells over the 21 days of exposure and recovery. This fact coincides with the lower rate of mitochondrial activity detected in the animals' telencephalon (4.0 $\mathrm{mg} \mathrm{L}^{-1}$ in the 21 st day), which may be associated with the apoptotic intrinsic pathway activation. This mitochondrial function oscillation can promote the complete mitochondrial dysfunction of most telencephalic cells, generating the release of cytochrome $\mathrm{c}$ in the cell cytosol and resulting in the caspase and apoptosis activation, which reflects the dataset obtained in 21 days of exposure.

Countless authors have already associated the increased production of ROS as the main mechanism of action involved in the neurotoxicity caused by manganese exposure (Milatovic et al. 2007; Lebda et al. 2012), which can be mainly explained by preferential metal accumulation by cellular mitochondria (Gunter et al. 2006). Green and Reed (1998) and Martinez-Finley et al. (2013) reinforce our idea that ROS generation and the subsequent decrease in the mitochondrial membrane potential affect the mitochondrial permeability transition, leading to organelle swelling, rupture of the outer membrane, and the release of various apoptogenic factors in the cytosol.

It is noteworthy that after 30 days of recovery in decontaminated water, animals showed an increase in the mitochondrial activity in relation to the observed in 21 days. It may be associated with the observation of new cells due to the rapid neurogenesis occurring in the zebrafish (Ghosh and Hui 2016; Ogai et al. 2012), which can be triggered by the secondary role of cell proliferation that some caspases precisely play to compensate cell loss (Pérez-Garijo 2018). At the same time, we still observe the tendency to increase the rate of TUNEL positive cells, indicating that the increase in cell apoptosis can be persistent after a short period of recovery, even considering the great capacity of neural regeneration of the species.

Although such changes have been observed at the cellular level, they have not resulted in major behavioral changes, corroborating with a previous study performed in our laboratory using the same 
concentrations of $\mathrm{MnCl}_{2}$ (Rodrigues et al. 2020). The low incidence of behavioral changes reported in both studies can be justified by the fact that low concentrations of $\mathrm{MnCl}_{2}$ are not sufficiently capable of damaging motor neurons at a rate (greater than the natural rate) of neurogenesis in the zebrafish telencephalon. This occurs throughout the dorsal and ventral telencephalon in the zebrafish (Adolf et al. 2006), considering that proliferative periventricular zones are not only presented internally but also in the outer surface of the telencephalon (Wullimann and Mueller 2004). Locomotor changes have been reported in zebrafish exposed to manganese but in much higher concentrations, which do not represent environmental conditions (Altenhofen et al. 2017).

In our study, there was a tendency, especially at 14 and 21 days, for animals from the $4.0 \mathrm{mg} \mathrm{L}^{-1}$ group to explore a greater distance than the control at the top of the aquarium. It can indicate that $\mathrm{MnCl}_{2}$ may have acted as an anxiolytic, since it is expected that the contact with the new (tank test) could induce an anxious behavior in the animals. This behavior results in their permanence at the bottom of the aquarium for a longer time, carefully exploring the top, due to the greater risk of predation (Richendrfer et al. 2012). The same pattern was observed in adult zebrafish exposed for 96 hours at 63 and $126 \mathrm{mg} \mathrm{L}^{-1}$ of $\mathrm{MnCl}_{2}$ (Altenhofen et al. 2017). However, this behavioral parameter appears to be normalized after the recovery period in our study. Other authors reported the locomotor recovery and exploratory functions in adult zebrafish submitted to hypoxia conditions after 3 hours of exposure in normoxic conditions (Braga et al. 2013). Manuel and collaborators (2015) also reported the reduction of anxious behavior after a recovery period associated with environmental enrichment. Therefore, we can conclude that behavioral changes are liable to partial and/or total reversion when facing a decontaminated or normalized environment within the specific standards of the species, even if the cellular level changes are permanent and irreversible.

Among these persistent damages, we can highlight the intestinal histopathological changes observed in our study. The percentage of villi with leukocyte infiltration and increased epithelial thickness remained higher in animals exposed to both concentrations of $\mathrm{MnCl}_{2}$ compared to the animals in the control group in all sampling periods of the experiment, including after the recovery period. Both histological findings are common in the intestinal inflammation described for the species (Brugman et al. 2009; Zhao and Pack 2007). The increase in intestinal villi may have occurred as a manner to adapt to the fish exposure environment in order to reduce the entry of $\mathrm{MnCl}_{2}$ from the intestinal lumen into the circulation (Abraham and Cho 2009). It may even result in milder damage in the other organs, since the metal ingestion by fish can also occur through the ingestion of contaminated food and particulate matter, besides through ion exchange, gills, and skin (Cáceres-Vélez et al. 2019).

We emphasize that the increase in intestinal cell infiltration, i.e., the presence of inflammation in animals exposed to $4.0 \mathrm{mg} \mathrm{L}^{-1}$ of $\mathrm{MnCl}_{2}$, occurred in the same experimental periods in which we observed a better exploration behavior in the upper zone of the aquarium ( 14 and 21 days, although no statistical difference was detected in 21 days). Some authors have already speculated the influence of the gut on 
zebrafish behavior, especially regarding the issue of intestinal microbiota (Davis et al. 2019), which is essential for normal stress responsiveness and anxiety-related behavior (Luczynski et al. 2016).

Although we did not make such analysis in our study, it has shown that manganese reduces the richness of intestinal bacteria (Wang et al. 2020a), resulting in the intestinal and nervous system inflammation through the entry of metal into the bloodstream and hematoencephalic barrier (Wang et al. 2020b). It can also result in neurodegeneration by promoting amyloid formation or increasing inflammatory responses to endogenous neuronal amyloid (Friedland and Chapman 2017), which has also been associated with $\mathrm{MnCl}_{2}$ exposure (Wang et al. 2020a). Therefore, the intestinal inflammation and/or the possible alteration in the intestinal microbiota derived from the $\mathrm{MnCl}_{2}$ exposure may have modulated the locomotor behavior of our animals, as it had already occurred in another study carried out with cadmium, for example (Xia et al. 2020).

When absorbed by the intestine, manganese enters the bloodstream and is transported to the liver through the portal vein (Barceloux 1999). Regardless the absorption pathway, the liver is one of the tissues with greater mitochondrial activity leading to manganese accumulation (Williams et al. 2012). Thus, this organ has proved to be useful in the histopathological evaluation of animals.

Some authors believe that histopathological damages in animals' organs exposed to some pollutants may be due to biochemical damages (Macêdo et al. 2020). Hepatocyte vacuolization, for example, is associated with the protein synthesis inhibition, depletion of energy, microtubules disintegration, or changes in the substrate use (Hinton and Lauren 1990). Studies have shown that fish hepatocytes tend to be more vacuolated than mammalian hepatocytes, especially in animals kept in captivity, due to artificial diet and housing conditions (Ferguson 1989; Gingerich 1982).

Besides this adversity, animals treated with both concentrations of $\mathrm{MnCl}_{2}$ demonstrated a high rate of cell vacuolization compared to the control animals, indicating a higher glycogen or lipid content in their hepatocytes. It may evolve to cell degeneration when the content (glycogen or lipid) accumulates to the point of distention of the hepatocyte cytoplasm, resulting in cytomegaly (Wolf and Wheeler 2018). In our study, after the recovery period, animals exposed to $0.5 \mathrm{mg} \mathrm{L}^{-1}$ demonstrated an improvement in the recovery rate, even compared to the 72-hour group. However, the specimens of the concentration of 4.0 $\mathrm{mg} \mathrm{L}^{-1}$ remained with a very high hepatocyte vacuolization rate.

This response pattern difference may be associated with the relatively smaller capacity of fish (in relation to mammals) to metabolize xenobiotic substances, by eliminating such unchanged substances through their gills (Parkinson 2008; Wolf and Wolf 2005). Therefore, we believe that at the lowest exposure concentration, fishes in our study may have had the ability to not completely metabolize the metal available in the water. The ability to recover/neutralize the rate of vacuolated hepatocytes in animals exposed to $0.5 \mathrm{mg} \mathrm{L}^{-1}$ and the degeneration in $4.0 \mathrm{mg} \mathrm{L}^{-1}$ specimens may have been triggered by the activity of antioxidant defense enzymes, such as superoxide dismutase (Wang et al. 2014). 
The same pattern of response was observed in the behavior of the studied offspring, as the main behavioral changes were observed at $5 \mathrm{dpf}$ and $7 \mathrm{dpf}$. It indicates that the damage to the locomotor system also does not appear to be persistent, which can be justified by the absence of the apoptosis increase in the encephalic region of the larvae evaluated with $\mathrm{AO}$. Although there was a generational transposition of some damages, these alterations do not persist after 10 days of life of these larvae, indicating that the next generations of adults from parents exposed to low concentrations of this pollutant may not undergo major changes in their biology.

As we look back at the initial aim of our study, the monitoring over different experimental periods allowed us to identify that the observed effects, especially in $4.0 \mathrm{mg} \mathrm{L}^{-1}$ of $\mathrm{MnCl}_{2}$, began to be expressed by the animals after a subchronic exposure of 14 days, which reflected in behavioral, intestinal, and mitochondrial changes, whereas the damage in the liver was observed after 72 hours of exposure.

Some of these damages were reversed after the recovery period, for example, anxiolytic behavior and intestinal damage. However, cell vacuolization in hepatocytes remained too high in the $4.0 \mathrm{mg} \mathrm{L}^{-1}$ group even after recovery. This liver overload, which remained even after recovery, could activate other biochemical and morphological changes in the animals over time. The chronic exposure of adult animals to $\mathrm{MnCl}_{2}$ resulted in some small changes in the larval behavior of the offspring, which were attenuated during development. Therefore, according to the parameters evaluated, we can conclude that the generational transposition of the damage caused by these environmentally relevant concentrations of $\mathrm{MnCl}_{2}$ is not very active, at least in these exposure times.

\section{Declarations}

\section{Declaration of Interest}

The authors declare no conflicts of interest.

\section{Funding}

Fundação de Amparo à Pesquisa do Estado do Rio Grande do Sul - FAPERGS and Feevale University through the granting of doctorate and undergraduate scholarships. This study was financed in part by the Coordenação de Aperfeiçoamento de Pessoal de Nível Superior - Brasil (CAPES) - finance code 001.

\section{Availability of Data and Material}

The data that support the findings of this study are available from the corresponding author on request.

\section{Author Contributions:}

Gabriela Zimmermann Prado Rodrigues: Conceptualization, Data curation, Formal analysis, Investigation, Methodology, Visualization, Writing - original draft, Writing - review \& editing. Thainá Garbino dos Santos: Methodology, Data curation. Mariana Finkler: Methodology. Jorge Henrique Burghausen: 
Methodology. Diulliane de Jesus Borba: Methodology. Luciane Beatris Mentges Staudt: Methodology. Bruna Bueno Milanesi: Methodology. Anelise Schneider. Methodology. Rafael Linden: Methodology. Léder Leal Xavier. Formal analysis, Visualization, Writing - review \& editing. Ana Luiza Ziulkoski: Formal analysis, Visualization. Diogo Losch de Oliveira: Formal analysis, Visualization. Günther Gehlen: Conceptualization, Funding acquisition, Project administration, Supervision, Writing - review \& editing.

\section{References}

1. Abraham C, Cho JH (2009) Mechanisms of Disease - Inflammatory Bowel Disease. The new England journal of medicine 361(21):2066-2078. doi:10.1056/NEJMra0804647

2. Adolf B, Chaputon P, Lam CS, Topp S, Tannhâuser B, Strãhle U, Götz M, Bally-Cuif L (2006) Conserved and acquired features of adult neurogenesis in the zebrafish telencephalon. Dev Biol 295(1):278293. doi:10.1016/j.ydbio.2006.03.023

3. Altenhofen S, Wiprich MT, Nery LR, Leite CE, Vianna MRMR, Bonan CD (2017) Manganese (II) chloride alters behavioral and neurochemical parameters in larvae and adult zebrafish. Aquat Toxicol 182:172-183. doi:10.1016/j.aquatox.2016.11.013

4. Alvarez-Bastida C, Martínez-Miranda V, Solache-Ríos M, Linares-Hernández I, Teutli-Siqueira A, Vázquez-Mejía G (2018) Drinking water characterization and removal of manganese. Removal of manganese from water. J Environ Chem Eng 6:2119-2125. doi:10.1016/j.jece.2018.03.019

5. Arndt A, Borella MI, Espósito BP (2014) Toxicity of manganese metallodrugs toward Danio rerio. Chemosphere 96:46-50. 10.1016/j.chemosphere.2013.07.014

6. Aschner M, Gannon M (1994) Manganese (Mn) transport across the rat blood-brain barrier: saturable and transferrin-dependent transport mechanisms. Brain Res Bull 33(3):345-349. doi:10.1016/03619230(94)90204-6

7. Associação B, de Normas Técnicas ABNT (2011) Ecotoxicologia Aquática e Toxicidade Aguda Método de Ensaio com peixes. NBR 15088, Rio de Janeiro, Brasil

8. Bacquart T, Frisbie S, Mitchell E, Grigg L, Cole C, Small C, Sarkar B (2015) Multiple inorganic toxic substances contaminating the groundwater of Myingyan Township, Myanmar: Arsenic, manganese, fluoride, iron, and uranium. Sci Total Environ 517:232-245. doi:10.1016/j.scitotenv.2015.02.038

9. Baggio S, Zenki K, Silva AM, Santos TG, Rech G, Lazzarotto G, Dias RD, Mussulini RBD, Rico EP, Olivera DL (2020) Fetal alcohol spectrum disorders model alters the functionality of glutamatergic neurotransmission in adult zebrafish. NeuroToxicology 78:152-160.

doi:10.1016/j.neuro.2020.03.003

10. Barceloux DG. Manganese (1999) J Toxicol Clin 37:293-307. doi:10.1081/CLT-100102427

11. Bernet D, Schmidt H, Meier W, Burkhardt- Holm P, Wahli T (1999) Differential modulation of cellular antioxidant status in zebrafish liver and kidney exposed to low dose arsenic trioxide. J Fish Dis 22:25-34. doi:10.1016/j.ecoenv.2016.09.025 
12. Bjørklund G, Chartrand MS, Aaseth J (2017) Manganese exposure and neurotoxic effects in children. Environ Res 155:380-384. doi:10.1016/j.envres.2017.03.003

13. Bouchard MF, Surette C, Cormier P, Foucher D (2018) Low level exposure to manganese from drinking water and cognition in school-age children. NeuroToxicology 64:110-117. doi:10.1016/j.neuro.2017.07.024

14. Braga MM, Rico EP, Córdova SD, Pinto CD, Blaser RE, Dias RD, Rosemberg DB, Oliveira DL, Souza DO (2013) Evaluation of spontaneous recovery of behavioral and brain injury profiles in zebrafish after hypoxia. Behav Brain Research 253:145-151. doi:10.1016/j.bbr.2013.07.019

15. Brown S, Taylor NL (1999) Could mitochondrial dysfunction play a role in manganese toxicity? Environ. Toxicol Pharmacol 7(1):49-57. doi:10.1016/s1382-6689(98)00054-4

16. Brugman S, Liu K, Lindenbergh-Kortleve D, Samsom JN, Furuta GT, Renshaw SA, Willemsen R, Nieuwenhuis ES (2009) Oxazolone-Induced Enterocolitis in Zebrafish Depends on the Composition of the Intestinal Microbiota. Gastroenterology 137(5):1757-1767. doi:10.1053/j.gastro.2009.07.069

17. Cáceres-Vélez PR, Fascineli ML, Rojas E, Meyer T, Venus T, Grisolia CK, Estrela-Lopis I, Moya S, Morais PC, Azevedo RB (2019) Impact of humic acid on the persistence, biological fate and toxicity of silver nanoparticles: A study in adult zebrafish. Environ Nanotechnol Monit Manag 12:100234. doi:10.1016/j.enmm.2019.100234

18. Dalzochio T, Rodrigues GZP, Simões LAR, Souza MS, Petry IE, Andriguetti NB, Silva GJH, Silva LB, Gehlen G (2018) In situ monitoring of the Sinos River, southern Brazil: water quality parameters, biomarkers, and metal bioaccumulation in fish. Environ Sci Pollut Res 25:9485-9500. doi:10.1007/s11356-018-1244-7

19. Davis DJ, Bryda EC, Gillespie CH, Ericsson AC (2016) Microbial modulation of behavior and stress responses in zebrafish larvae. Behav Brain Res 311:219-227. doi:10.1016/j.bbr.2016.05.040

20. Ferguson HW (1989) Systemic Pathology of Fish: A Text and Atlas of Comparative Tissue Responses in Diseases of Teleosts. lowa State Pr, Ames

21. Filippi-Chiela EC, Oliveira MM, Jurkovski B, Callegari-Jacques SM, Silva VD, Lenz G (2012) Nuclear Morphometric Analysis (NMA): Screening of Senescence, Apoptosis and Nuclear Irregularities. PLoS ONE 7(8):e42522. doi:10.1371/journal.pone.0042522

22. Friedland RP, Chapman MR (2017) The role of microbial amyloid in neurodegeneration. PLoS Pathog 13(12):e1006654. doi:10.1371/journal.ppat.1006654

23. Frisbie SH, Mitchell EJ, Dustin H, Maynard DM, Sarkar B (2012) World health organization discontinues its drinking-water guideline for manganese. Environ Health Perspect 120(6):775-778. doi:10.1289/ehp.1104693

24. Gatachew B, Csoka AB, Aschner M, Tizabi $Y$ (2019) Nicotine protects against manganese and ironinduced toxicity in SH-SY5Y cells: Implication for Parkinson's disease. Neurochem Int 124:19-24. doi:10.1016/j.neuint.2018.12.003

25. Gavin CE, Gunter KK, Gunter TE (1999) Manganese and calcium transport in mitochondria: implications for manganese toxicity. Neurotoxicology 20:445-453 
26. Ghosh S, Hui SP (2016) Regeneration of Zebrafish CNS: Adult Neurogenesis. Neural Plast. 2016: 5815439. doi: 10.1155/2016/5815439

27. Gingerich WH, Weber LJ (1982) Hepatic toxicology of fishes. Aquat Toxicol. 55-105

28. Green DR, Reed JC (1998) Mitochondria and apoptosis. Science 281:1309-1312

29. Gunter TE, Gavin CE, Aschner M, Gunter KK (2006) Speciation of manganese in cells and mitochondria: A search for the proximal cause of manganese neurotoxicity. Neurotoxicology 27(5):765-776. doi:10.1016/j.neuro.2006.05.002

30. Hazardous Substances Data Bank (HSDB) (2001) Manganese compounds. Bethesda MD, Available at http://toxnet.nlm.nih.gov/cgi-bin/sis/htmlgen?HSDB

31. Hinton DE, Laurén DJ (1990) Integrative histopathological approaches to detecting effects of environmental stressors on fishes. Am. Fisheries Soc. Symp. 8: 51-66

32. ISO International Organization for Standardization (1996) Water quality - determination of the acute lethal toxicity of substances to a freshwater fish [Brachydanio rerio Hamilton-Buchanan (Teleostei, Cyprinidae)]. ISO 7346-3: Flowthrough method, Available at http://www.iso.org

33. lyare PU The effects of manganese exposure from drinking water on school-age children: A systematic review. NeuroToxicology. 73: 1-7. doi: 10.1016/j.neuro.2019.02.013

34. Jia M, Wang Y, Wang D, Teng M, Yan J, Yan S, Meng Z, Li R, Zhou Z, Zhu W (2019) The effects of hexaconazole and epoxiconazole enantiomers on metabolic profile following exposure to zebrafish (Danio rerio) as well as the histopathological changes. Chemosphere 226:520-533. doi:10.1016/j.chemosphere.2019.03.140

35. Kakoi B, Kaluli JW, Ndiba P, Thiong'o G (2016) Banana pith as a natural coagulant for polluted river water. Ecol Eng 95:699-705. doi:10.1016/j.ecoleng.2016.07.001

36. Kawamura R, Ikuta H, Fukuzumi S, Yamada R, Tsubaki S, Kodama T, Kurata S (1941) Intoxication by Manganese in Well Water. Kitasato Arch Exp Med 18(3):145-169

37. Kawan A, Zhang T, Liu W, Mukhtar H, Zhan C, Zhang X (2019) Recovery of reproductive function of female zebrafish from the toxic effects of microcystin-LR exposure. Aquat Toxicol 214:105240. doi:10.1016/j.aquatox.2019.105240

38. Krützmann MW, Machado AB, Constante MS, Rigo KA, Perassolo MS, Osório DMM, Berlese DB (2020) Evaluation of the effects of fluoride and associated with lead in animal model and physicalchemical analysis of public supply water and of the Sinos River in the South of Brazil. International Journal for Innovation Education Research 8(4):295-322. 10.31686/ijier.vol8.iss4.2290

39. Kwakye GF, Paoliello MBM, Mukhopadhyay S, Browman AB, Aschner M Manganese-induced parkinsonism and Parkinson's disease: shared and distinguishable features. Int. J. Environ. Res. 12(7): 7519-7540. doi: 10.3390/ijerph120707519

40. Lebda MA, El-Neweshy MS, El-Sayed YS (2012) Neurohepatic toxicity of subacute manganese chloride exposure and potential chemoprotective effects of lycopene. NeuroToxicology 33(1):98104. doi:doi.org/10.1016/j.neuro.2011.12.008 
41. Li DL, Huang YJ, Gao S, Chen LQ, Zhang ML, Du ZY (2019) Sex-specific alterations of lipid metabolism in zebrafish exposed to polychlorinated biphenyls. Chemosphere 221:768-777. doi:10.1016/j.chemosphere.2019.01.094

42. Li G, Ma X, Chen R, Yu Y, Tao H, Shi B (2019) Field studies of manganese deposition and release in drinking water distribution systems: Insight into deposit control. Water Research 163:114897. doi:10.1016/j.watres.2019.114897

43. Liu Z, Liu K, Liu Z, Cong L, Lei M, Ma Z, Li J, Deng Y, Liu W, Xu B (2021) Manganese-induced alphasynuclein overexpression aggravates mitochondrial damage by repressing PINK1/Parkin-mediated mitophagy. Food Chemical Toxicology 152:112213. doi 10.1016/j.fct.2021.112213

44. Luczynski P, McVey Neufeld KA, Oriach CS, Clarke G, Dinan TG, Cryan JF (2016) Growing up in a bubble: using germ- free animals to assess the influence of the gut microbiota on brain and behavior. Int J Neuropsychopharmacol 19(8). doi:10.1093/ijnp/pyw020

45. Macêdo AKS, Santos KPE, Brighenti LS, Windmöller CC, Barbosa AR, Ribeiro RIMA, Santos HB, Thomé RG (2020) Histological and molecular changes in gill and liver of fish (Astyanax lacustris Lütken, 1875) exposed to water from the Doce basin after the rupture of a mining tailings dam in Mariana, MG, Brazil. Sci Total Environ 735:139505. doi:10.1016/j.scitotenv.2020.139505

46. Manuel R, Gorissen M, Stokkermans M, Zethof J, Ebbesson LOE, Vis H, Boss R (2015) The effects of environmental enrichment and age-related differences on inhibitory avoidance in zebrafish (Danio rerio Hamilton). Zebrafish 12(2). doi:10.1089/zeb.2014.1045

47. Marsidi N, Hasan HA, Abdulah SRS (2018) A review of biological aerated filters for iron and manganese ions removal in water treatment. J Water Process Eng 23:1-12. doi:10.1016/j.jwpe.2018.01.010

48. Martinez-Finley EJ, Gavin CE, Aschner M, Gunter TE (2013) Manganese neurotoxicity and the role of reactive oxygen species. Free Radic Biol Med 62:65-75. doi:10.1016/j.freeradbiomed.2013.01.032

49. Martinou JC, Youle RJ (2011) Mitochondria in Apoptosis: Bcl-2 Family Members and Mitochondrial Dynamics. Dev Cell 21(1):92-101. doi:10.1016/j.devcel.2011.06.017

50. Mena I, Manganese (1980) In: Waldron HA (ed) Metals in the environment. 1st edn. London: Academic Press, pp 199-220

51. Miah MR, ljomone OM, Okoh COA, ljomone OK, Akingbade GT, Ke T, Krum B, Martins AC Jr, Akinyemi A, Aranoff N, Soares FAA, Bowman AB, Aschner M (2020) The effects of manganese overexposure on brain health. Neurochem Int 135:104688. doi:10.1016/j.neuint.2020.104688

52. Milatovic D, Yin Z, Gupta RC, Sidoryk M, Albrecht J, Aschner JL, Aschner M (2007) Manganese Induces Oxidative Impairment in Cultured Rat Astrocytes. Toxicol Sci 98(1):198-205. doi:10.1093/toxsci/kfm095

53. Ogai K, Hisano F, Mawatari K, Sugitani K, Koriyama Y, Nakashima H, Kato S (2012) Upregulation of anti-apoptotic factors in upper motor neurons after spinal cord injury in adult zebrafish. Neurochem Int 61:1201-1211. doi:10.1016/j.neuint.2012.08.015 
54. Oliveira DA, Galvão P (2019) Geometry and water quality of the unconfined aquifer near the Piracicaba river, Ipatinga/MG. Brazil HydroResearch 2:31-39. doi:10.1016/j.hydres.2019.11.003

55. Parkinson A, Ogilvie BW (2008) Biotransformation of xenobiotics. In: Casarett LJ, Doull J et al (eds) Casarett and Doull's Toxicology: The Basic Science of Poisons, 7. McGraw-Hill, New York, pp 161304

56. Patil DS, Chavan SM, Oubagaranadin JUK (2016) A review of technologies for manganese removal from wastewaters. J Environ Chem Eng 4:468-487. doi:10.1016/j.jece.2015.11.028

57. Peres TV, Schettinger MRC, Chen P, Carvalho F, Avila DS, Bowman AB, Aschner M (2016) Manganeseinduced neurotoxicity: a review of its behavioral consequences and neuroprotective strategies. BMC Pharmacol Toxicol 17:57. doi:10.1186/s40360-016-0099-0

58. Perez-Garijo A (2018) When dying is not the end: Apoptotic caspases as drivers of proliferation. Semin Cell Dev Biol 82:86-95. doi:10.1016/j.semcdb.2017.11.036

59. Qian L, Feng C, Yang Y, Liu Y, Qi S, Wang C (2018) Mechanisms of developmental toxicity in zebrafish embryos (Danio rerio) induced by boscalid. Sci Total Environ 634:478-487. doi:10.1016/j.scitotenv.2018.04.012

60. Richendrfer H, Pelkowski SD, Colwill RM, Creton R (2012) On the edge: Pharmacological evidence for anxiety-related behavior in zebrafish larvae. Behav Brain Res 228:99-106. doi:10.1016/j.bbr.2011.11.041

61. Rietzler AC, Fonseca AL, Lopes GP (2001) Heavy metals in tributaries of Pampulha Reservoir, Minas Gerais. Brazilian Journal of Biology 61(3):363-370. doi:10.1590/S1519-69842001000300004

62. Rodrigues GZP, Souza MS, Silva AH, Zwetsch BG, Gehlen G (2018) Evaluation of intestinal histological damage in zebrafish exposed to environmentally relevant concentrations of manganese. Ciência e Natura 40. doi:10.5902/2179460X31681

63. Rodrigues GZP, Staudt LBM, Moreira MG, Santos TG, Souza MS, Lúcio CJ, Panizzon J, Kayser JM, Simões LAR, Ziulkoski AL, Bonan CD, Oliveiera DL, Gehlen G (2020) Histopathological, genotoxic, and behavioral damages induced by manganese (II) in adult zebrafish. Chemosphere 244:125550. doi:10.1016/j.chemosphere.2019.125550

64. Roth JA, Garrick MD (2003) Iron interactions and other biological reactions mediating the physiological and toxic actions of manganese. Biochem Pharmacol 66(1):1-13. doi:10.1016/S00062952(03)00145-X

65. Sarkar S, Malovic E, Harischandra DS, Ngwa HA, Ghosh A, Hogan C, Rokad D, Zenitsky G, Jin H, Anantharam V, Kanthasamy AG, Kanthasamy A (2018) Manganese exposure induces neuroinflammation by impairing mitochondrial dynamics in astrocytes. NeuroToxicology, v. 64, p. 204-218, 2018. doi: 10.1016/j.neuro.2017.05.009

66. Solá S, Morgado AL, Rodrigues CMP (2013) Death receptors and mitochondria: Two prime triggers of neural apoptosis and differentiation. Biochem Biophys Acta 1830(1):2160-2166.

doi:10.1016/j.bbagen.2012.09.021 
67. Wang C, Youle RJ (2009) The role of mitochondria in apoptosis*. Annual review of genetics 43:95118. doi:10.1146/annurev-genet-102108-134850

68. Wang G, Shao J, Wu M, Meng Y, Gul Y, Yang H, Xiong D (2019) Effect of acute exposure of triazophos on histological structure and apoptosis of the brain and liver of zebrafish (Danio rerio). Ecotox Environ Safe 180:646-655. doi:10.1016/j.ecoenv.2019.05.053

69. Wang H, Yang F, Xin R, Cui D, He J, Zhang S, Sun Y (2020b) The gut microbiota attenuate neuroinflammation in manganese exposure by inhibiting cerebral NLRP3 inflammasome. Biomed Pharmacother 129:110449. doi:10.1016/j.biopha.2020.110449

70. Wang H, Zhang S, Yang F, Xin R, Wang S, Cui D, Sun Y (2020a) The gut microbiota confers protection in the CNS against neurodegeneration induced by manganism. Biomed Pharmacother 127:110150. doi:10.1016/j.biopha.2020.110150

71. Wang Q, Liu S, Hu D, Wang Z, Wang L, Wu T, Wu Z, Mohan C, Peng A (2016) Identification of apoptosis and macrophage migration events in paraquat-induced oxidative stress using a zebrafish model. Life Sciences 157:116-124. doi:10.1016/j.Ifs.2016.06.009

72. Wang YH, Xu X, Li H (2014) Hepatoprotective effects of Mimic of Manganese superoxide dismutase against carbon tetrachloride-induced hepatic injury. Int Immunopharmacol 22:126-132. doi:10.1016/j.intimp.2014.06.016

73. Williams M, Todd GD, Roney N, Crawford J, Coles C, Garey JD et al (2012) Toxicological Profile for Manganese, first edn. Agency for Toxic Substances and Disease Registry, Atlanta

74. Wolf JC, Wheeler JR (2018) A critical review of histopathological findings associated with endocrine and non-endocrine hepatic toxicity in fish models. Aquat Toxicol 197:60-78. doi:10.1016/j.aquatox.2018.01.013

75. Wolf JC, Wolfe MJ (2005) A Brief Overview of Nonneoplastic Hepatic Toxicity in Fish. Toxicologic Pathology 33(1):75-85. doi:10.1080/01926230590890187

76. Wu F, Yang H, Liu Y, Yang X, Xu B, Liu W, Xu Z, Deng Y (2020) Manganese exposure caused reproductive toxicity of male mice involving activation of $\mathrm{GnRH}$ secretion in the hypothalamus by prostaglandin E2 receptors EP1 and EP2. Ecotoxicol Environ Saf 201:110712. 10.1016/j.ecoenv.2020.110712

77. Wullimann MF, Mueller T (2004) Teleostean and mammalian forebrains contrasted: Evidence from genes to behavior. J Comp Neurol. 19;475(2):143 - 62. doi: 10.1002/cne.20183. Erratum in: J Comp Neurol. 2004 Oct 25;478(4):427-8

78. Wullimann MF, Rupp B, Reichert H (1996) Neuroanatomy of the Zebrafish Brain. Birkh€auser

79. Xia Y, Zhu J, Xu Y, Zhang H, Zou F, Meng X (2020) Effects of ecologically relevant concentrations of cadmium on locomotor activity and microbiota in zebrafish. Chemosphere 257:127220. doi:10.1016/j.chemosphere.2020.127220

80. Zhao X, Pack M (2007) Modeling intestinal disorders using zebrafish. In: Methods in Cell Biology. Methods Cell Biol 138:241-270. doi:10.1016/bs.mcb.2016.11.006 
81. Zhou X, Kosaba K, Nakanishi T, Welfringer T, Itoh S (2020) Manganese accumulation on pipe surface in chlorinated drinking water distribution system: Contributions of physical and chemical pathways. Water Research 184:116201. doi:10.1016/j.watres.2020.116201

\section{Figures}

A)

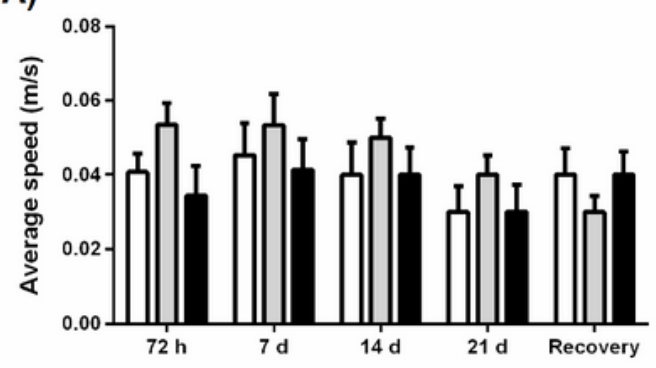

C)

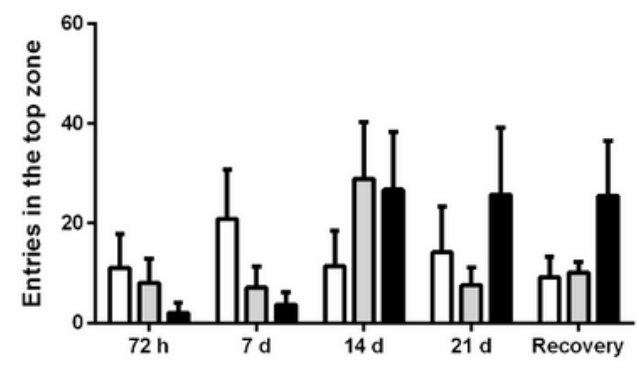

E)

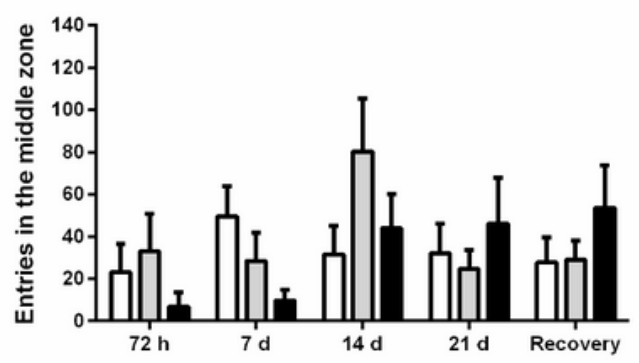

G)

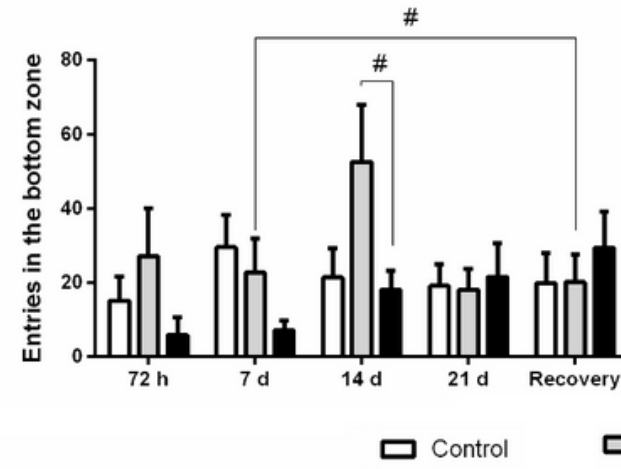

B)

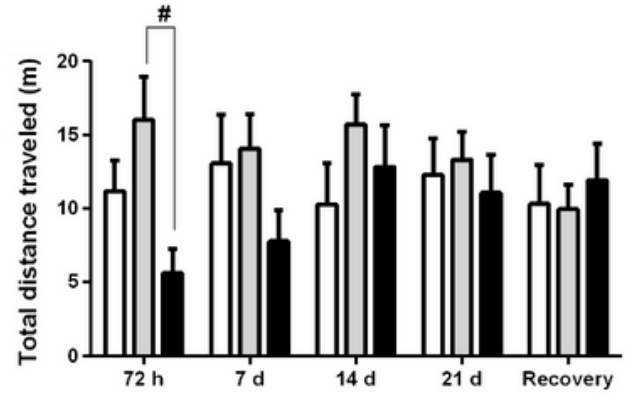

D)

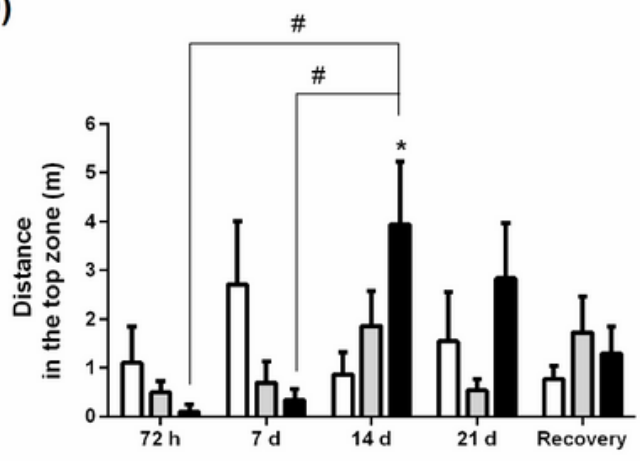

F)

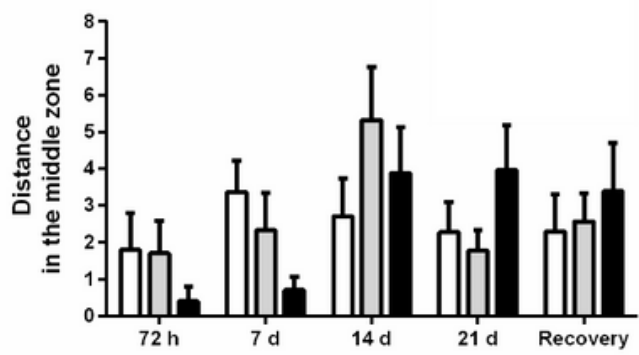

H)

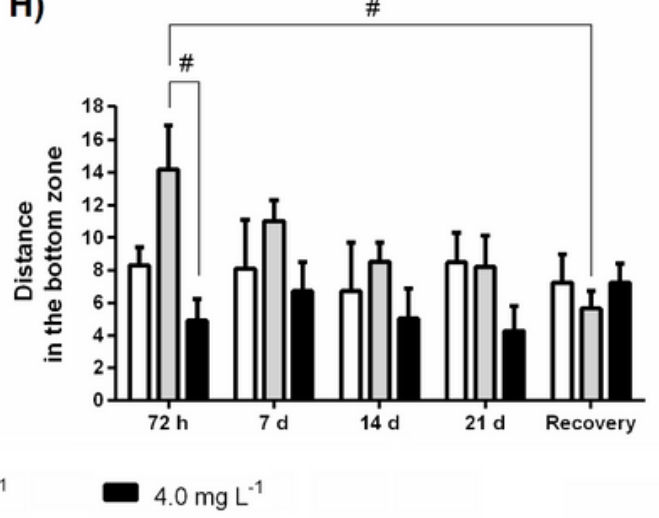

Figure 1 
Locomotor behavioral parameters evaluated in zebrafish exposed to $\mathrm{MnCl} 2$ and after recovery period. Data are expressed as mean and standard error. Asterisks $\left(^{*}\right)$ express significant differences from the control $(p<0.05)$, and other differences are represented by the symbol \# $(p<0.05)$

A)

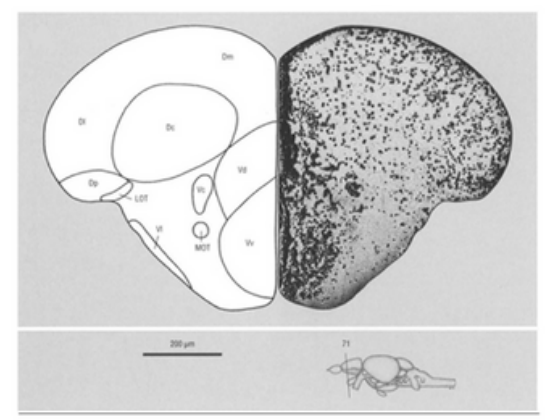

C)

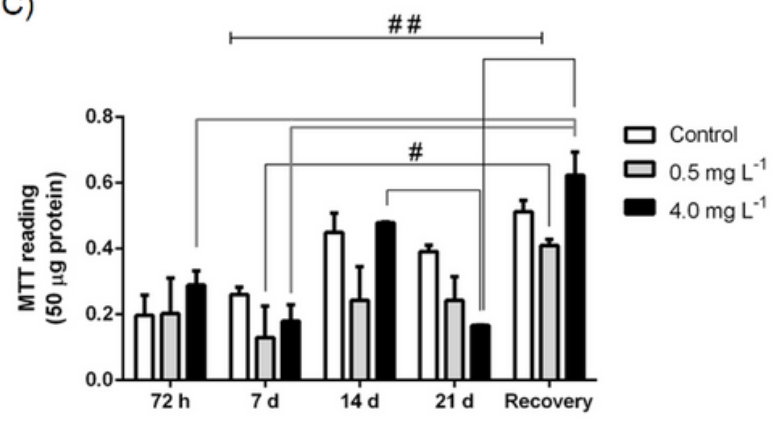

B)

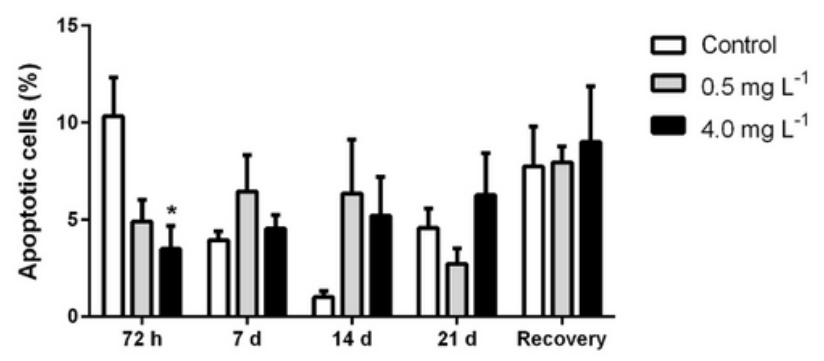

D)

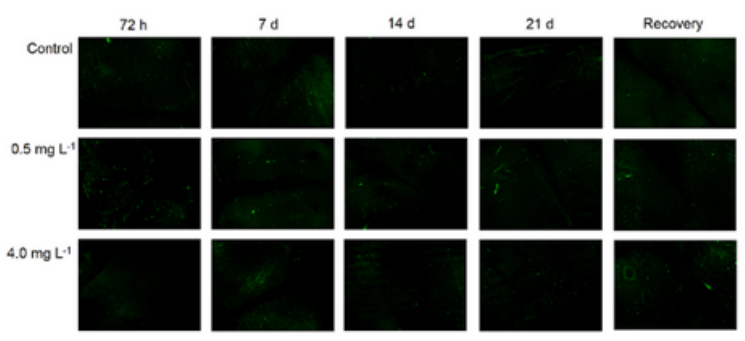

Figure 2

Representative figure of the data obtained by the MTT test and TUNEL staining. In A we can observe the telencephalic region of interest and used for TUNEL staining, obtained from the Wulliman's Neuroanatomy atlas (1996). In B, we can observe the values (mean and standard error) obtained in the quantification of TUNEL positive cells, which are illustrated in D. In C, we observe the values (mean and standard error) of the absorbances of the MTT assay, where the symbol (\#) represents a statistically significant difference between groups $(p<0.05)$ and \#\# represents $p<0.01$. 

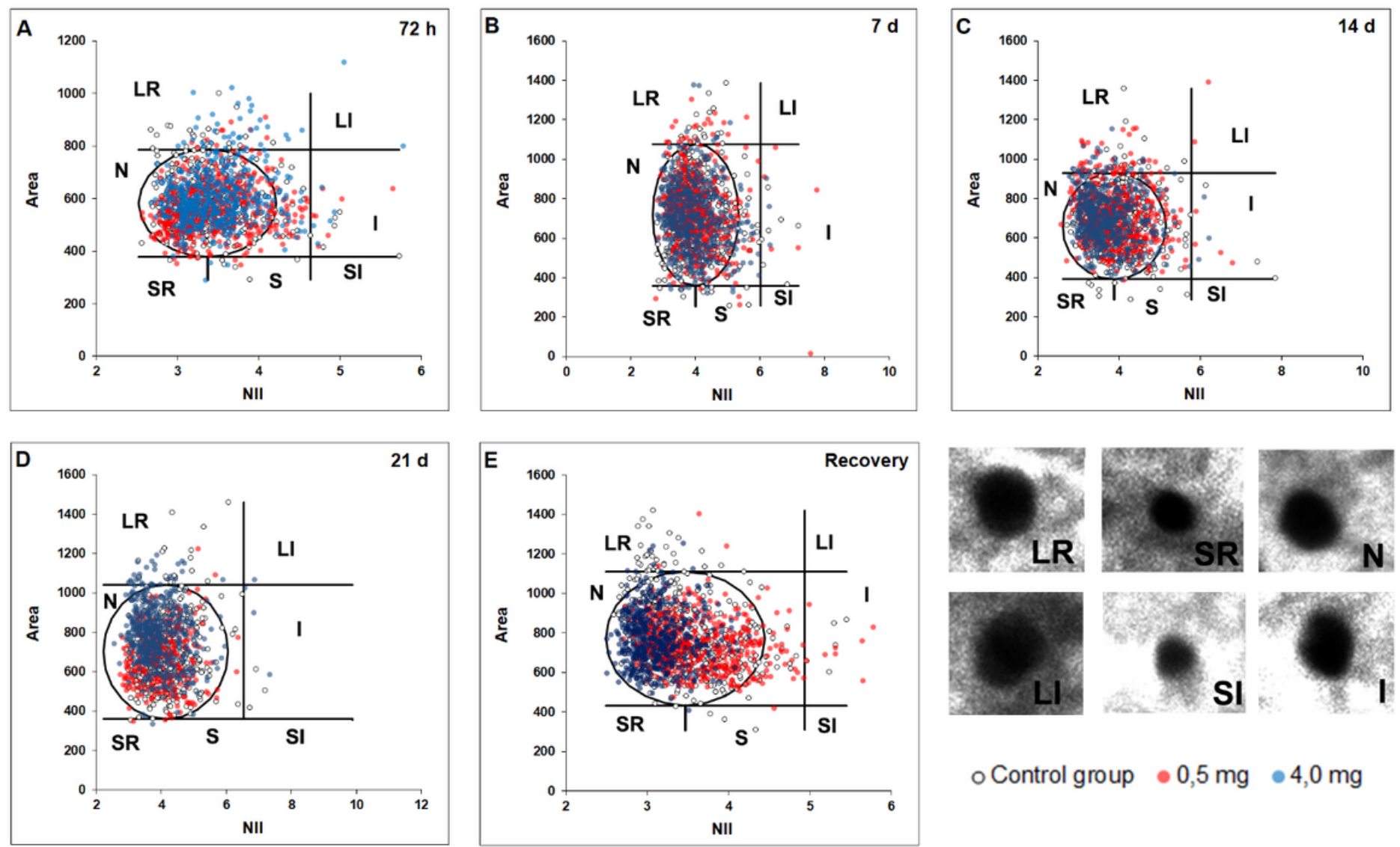

○Control group $\bullet 0,5 \mathrm{mg} \bullet 4,0 \mathrm{mg}$

\section{Figure 3}

In A: percentage of normal hepatocytes in $\mathrm{MnCl} 2$ concentrations compared to the control group (red line). Data are expressed as mean and standard error. Significant differences are represented by asterisks, with $* p<0.05$ and ${ }^{* *} p<0.01$. Differences between the sample periods are represented by uppercase and lowercase letters, with A being $0.05 \mathrm{mg} \mathrm{L}-1$ and B being $4.0 \mathrm{mg} \mathrm{L-1}$. In B-F: Figure showing the nuclear irregularity index (NII) over the periods of experimentation. We use the following classifications based on Filippi-Chiela and collaborators (2012). LR: large and regular. LI: large and irregular. I: irregular. SI: small and irregular. S: small. SR: small and regular 
A)

B)

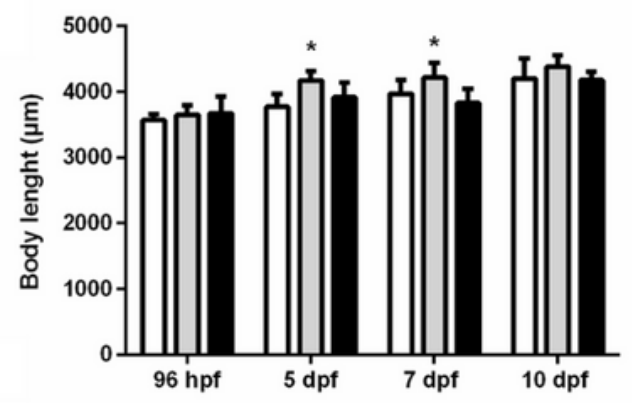

D)

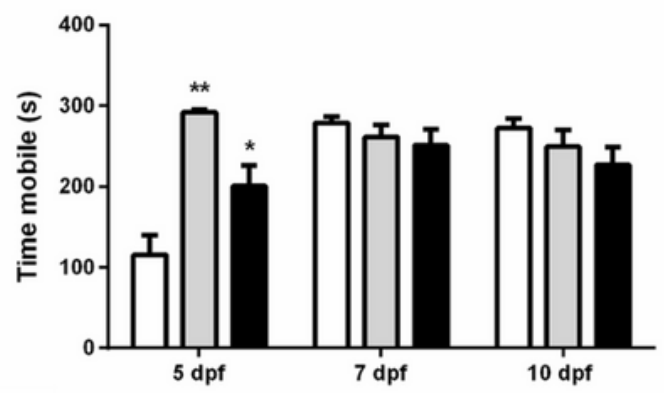

F)

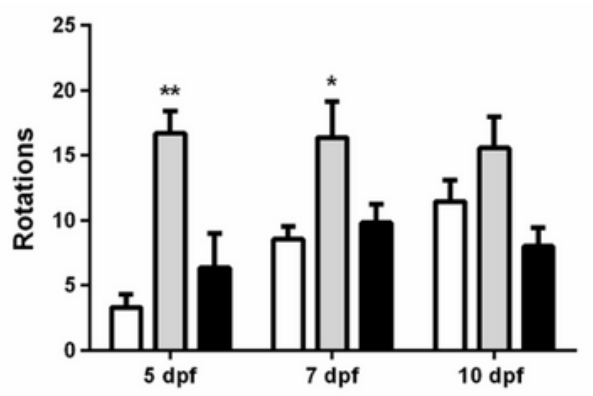

C)

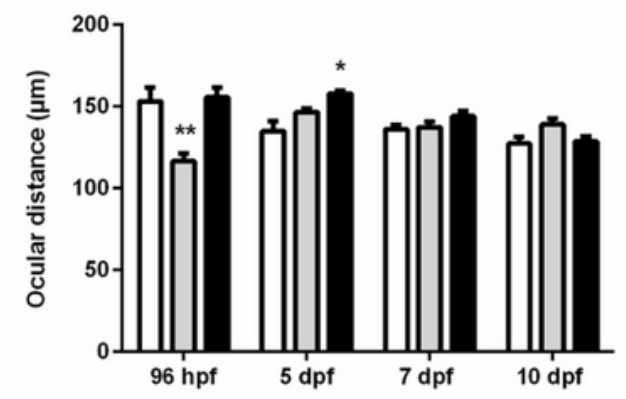

E)

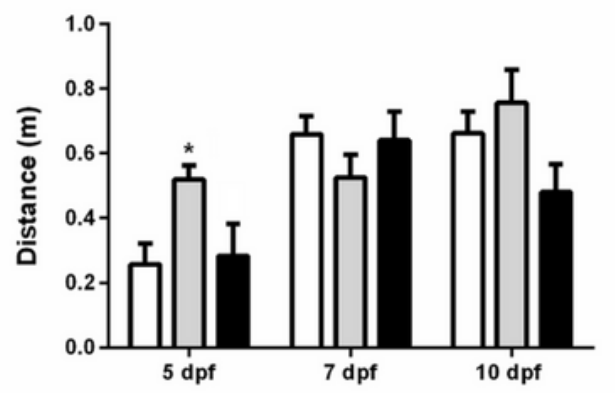

G)

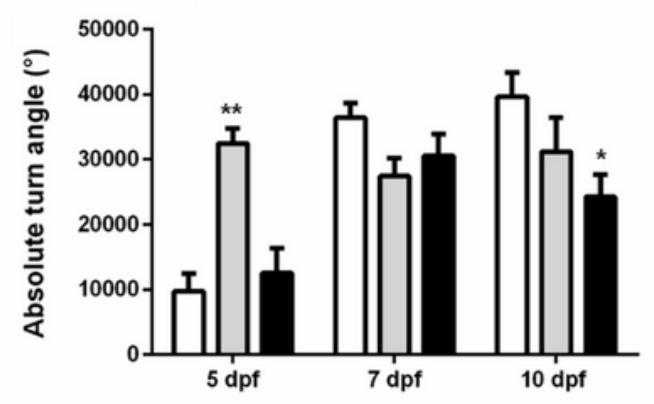

\section{Figure 4}

Scheme showing the method of measuring body length and ocular distance (A). Body length and ocular distance data in $B$ and $C$, and behavioral analyses performed on individuals in larval stages $(D, E, F$, and $G)$. The data are expressed as mean and standard error and significant differences in relation to the control are represented by asterisks (being * $=p<0.05$ and ${ }^{\star *}=p<0.01$ ) 


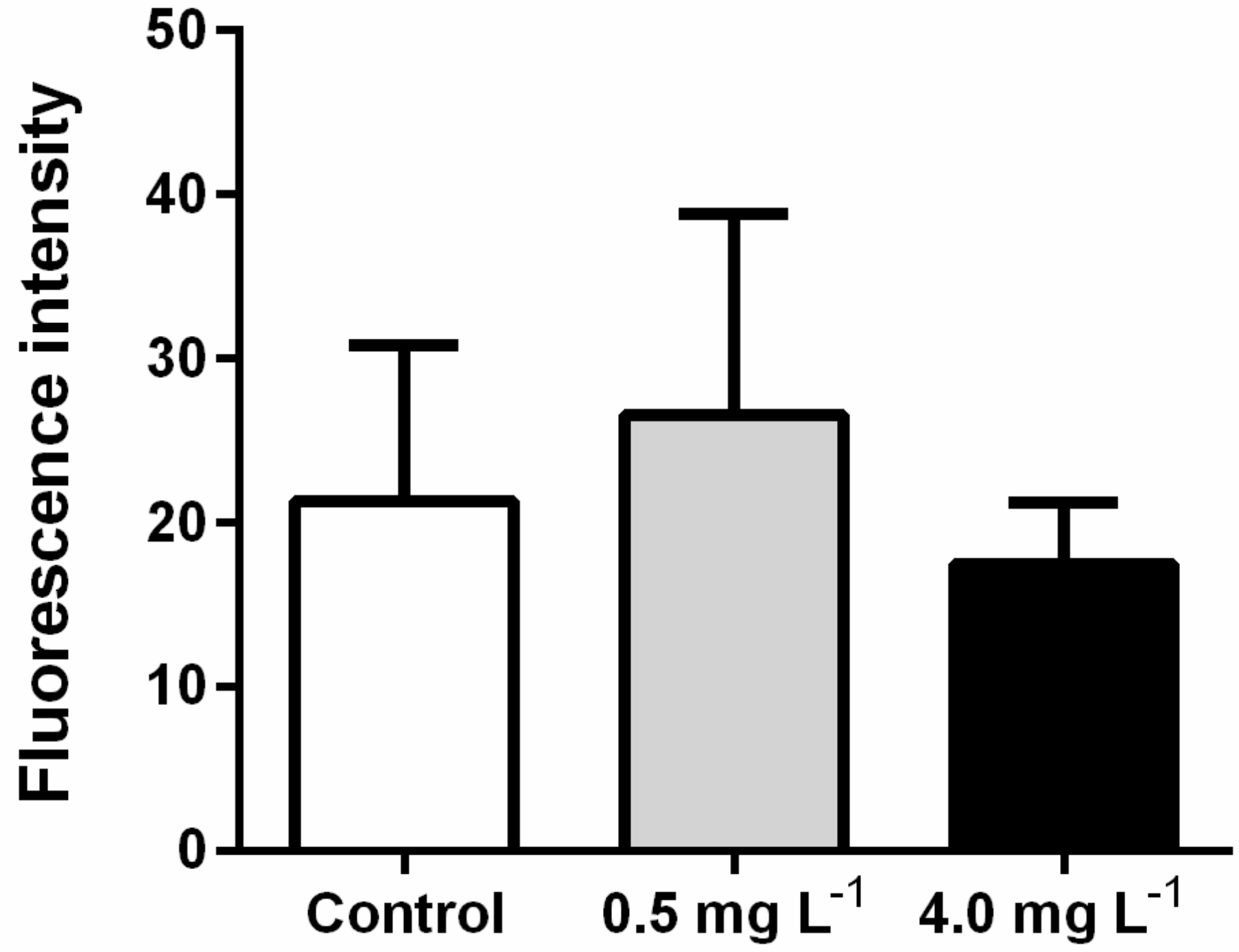

Figure 5

Fluorescence intensity observed in larvae stained with acridine orange. Data are expressed as mean and standard error

\section{Supplementary Files}

This is a list of supplementary files associated with this preprint. Click to download.

- SUPPLEMENTARYMATERIAL21.docx 